\title{
18th and 19th century dietary advice
}

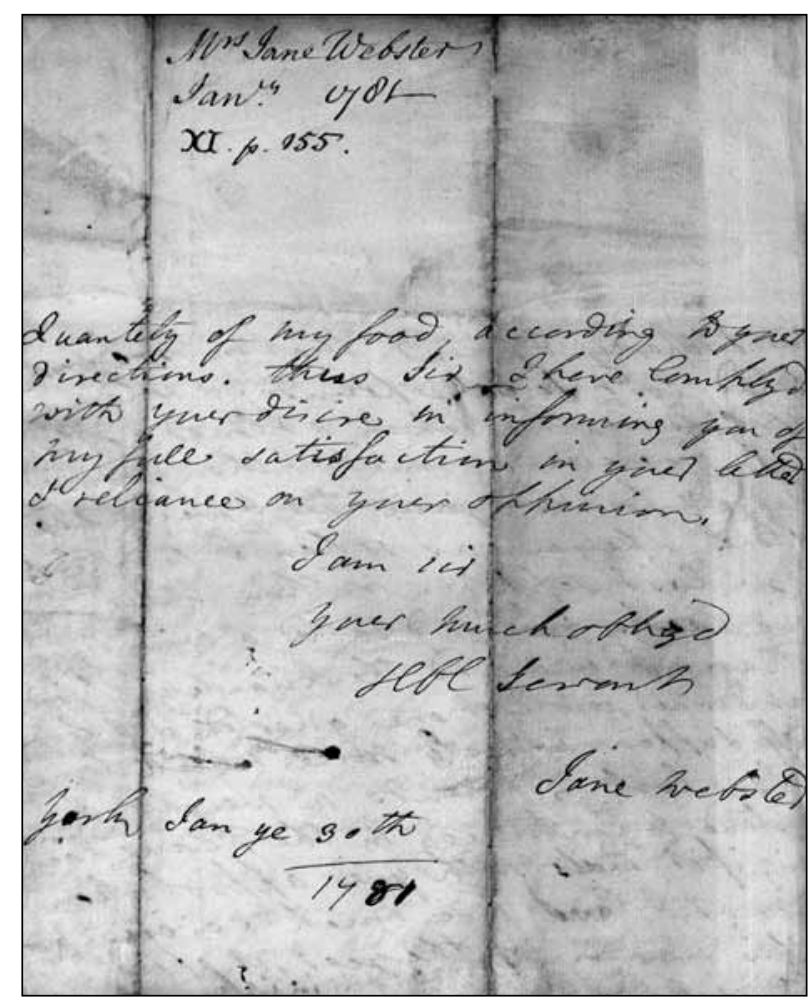

WILLIAM CULLEN'S CONSULTATION PRACTICE

RCPE President William Cullen (1710-1790) had an extensive 'consultation by letters' practice. The letters, which are kept today in the RCPE Library, will be available online in 2015.

One letter, from an overweight female patient, reads:

The question I wish you to determine upon is my plan to reduce my corpulency, till I am in a moderate state; that is till I may weigh about 12 stones instead of 15 and whether such a plan will be safe and of service to my health and to the prevention of further coughs and stuffing in my breast.

\section{Cullen replied:}

Corpulence certainly disposes to violent diseases. You should persist in your present measures till you make your body still lighter by two stone or more. For in a woman of middle size, anything above 12 stone is too much.

Judiciously continue the walking and even through the winter you must take a great deal of bodily exercise, avoiding however being over heated. Cold bathing is also proper and should be continued through the winter. Animal food only once a day and then very moderately. Cheat appetite by eating light things especially vegetables.
You should go on with exercise and diet till you are reduced to the weight mentioned. When this is done the same vigour will not be necessary provided you guard against relapsing into your former corpulence.

\section{OBESITY CARICATURES - WILLIAM WADD (I776- I 829)}

The Sibbald Library houses seven works written by William Wadd, a fellow of the Royal College of Surgeons of England and Surgeon Extraordinary to George IV.

They range from works on urology to his two collections of medically related stories, anecdotes and biographical sketches Nugae chirurgicae and Mems, Maxims and Memoirs.

Wadd's book on obesity and dietetics, Comments on Corpulency, was also very popular and went through many editions. Wadd describes a post-mortem examination of an obese person showing the obstruction caused to the heart by the fat in the abdomen.

William Wadd was a skilled artist who illustrated all his books himself. He died shortly after the publication of the Comments when he jumped from a runaway carriage on a holiday in Ireland.

lain Milne

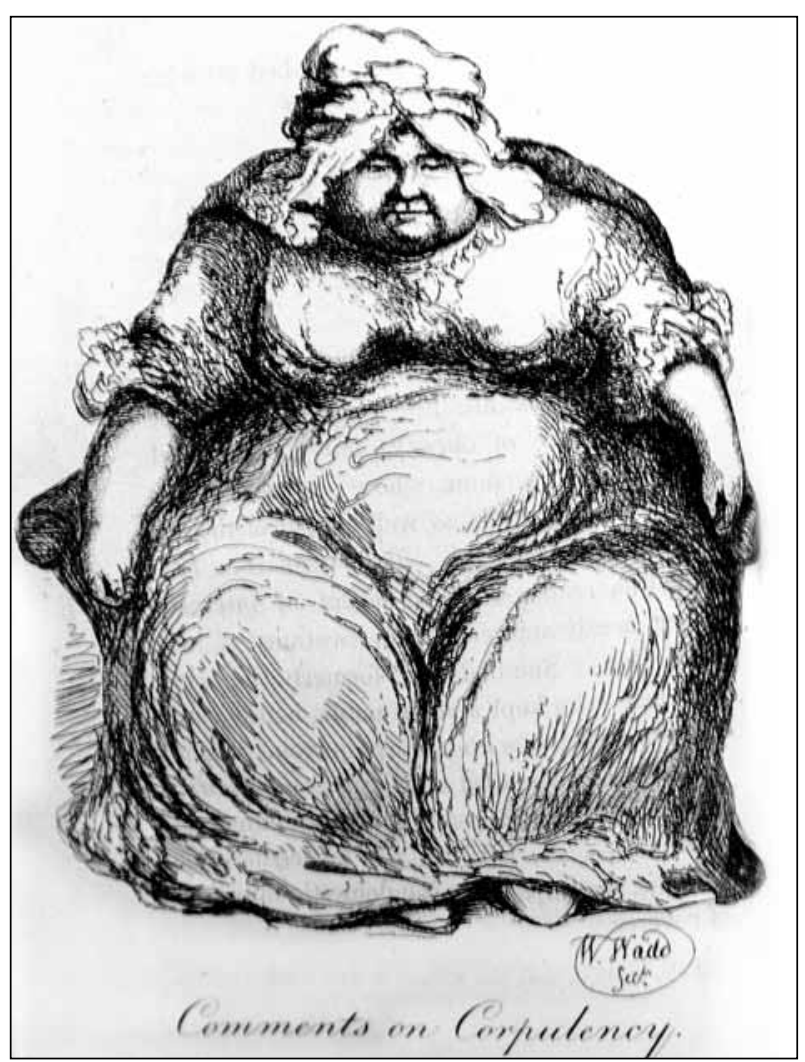

